\title{
Unconventional high-pressure Raman spectroscopy study of kinetic and peak pressure effects in plagioclase feldspars
}

\author{
Melissa Sims ${ }^{1,2}\left(\right.$ D Steven J. Jaret ${ }^{1,5} \cdot$ Jeffrey R. Johnson ${ }^{3} \cdot$ Matthew L. Whitaker ${ }^{1,4} \cdot$ Timothy D. Glotch $^{1}$
}

Received: 18 February 2019 / Accepted: 6 January 2020 / Published online: 31 January 2020

(c) The Author(s) 2020

\begin{abstract}
We present the results of a high-pressure semi-hydrostatic study of two plagioclase minerals, andesine and albite, using diamond anvil cells (DACs) to characterize in situ variations in Raman spectra under different static pressures. In this work, we also examined the kinetic effects on deformation at both long and short timescales through non-traditional experiments in which the DAC was either dropped or struck with a mallet. We examined the effects of strain rate, quench rate, and pressure duration on the Raman spectra of plagioclase. We observed that amorphization occurred in all the plagioclase samples we analyzed, and that amorphization onset and permanence differ depending on the composition, kinetics, energy input, and peak pressure. In andesine, samples pressurized above a peak pressure of $18 \mathrm{GPa}$, amorphization is permanent. Below this critical pressure, the phase has 'memory', and crystalline andesine reforms on decompression. Our findings suggest the presence of a thermodynamic energy well in andesine around $18 \mathrm{GPa}$, and we show that any additional energy input while close to $18 \mathrm{GPa}$ results in amorphization becoming permanent. The effect of the energy well may be relevant for longer duration impacts. For such impacts, equilibrium state studies of deformation and phase formation were previously considered to be applicable. These experiments illuminating the presence of memory effects in plagioclase have implications for comparing static compression, in which samples are measured while under compression, with shock compression, for which samples are measured after decompression.
\end{abstract}

Keywords Kinetic study $\cdot$ Plagioclase $\cdot$ High-pressure Raman spectroscopy $\cdot$ Albite $\cdot$ Andesine

\section{Introduction}

The structure and transformation of plagioclase at extreme conditions (high-pressure, high-temperature) have been of interest in meteoritics since the discovery of "maskelynite" in the shocked meteorite Shergotty (Tschermak 1872). While the origin of maskelynite has been the subject of debate

Melissa Sims

msims9@jhu.edu

1 Department of Geosciences, Stony Brook University, Stony Brook, NY 11794-2100, USA

2 Department of Earth and Planetary Sciences, Johns Hopkins University, Baltimore, MD 21218-2687, USA

3 Johns Hopkins University Applied Physics Laboratory, Laurel, MD 20723-6005, USA

4 National Synchrotron Light Source II, Brookhaven National Laboratory, Upton, NY 11973, USA

5 Department of Earth and Planetary Sciences, American Museum of Natural History, New York, NY 10024, USA
(Gillet and El Goresy 2013), it is generally considered to be a diaplectic plagioclase glass transformed by solid-state processes during shock events (Arndt et al. 1982; Bunch et al. 1967; Diemann and Arndt 1984; Gillet and El Goresy 2013; Hörz and Quaide 1973; Jaret et al. 2015; Milton and de Carli 1963). These glasses are commonly observed in association with impact events (DeCarli and Jamieson 1961; Milton and de Carli 1963; Williams and Jeanloz 1989). Shock pressures experienced during impact cratering events can significantly alter the crystal structure of many minerals (Chao 1968; French and Short 1968). Amorphous plagioclase is used as the indicator for the petrographic type or shock stage S5, indicating pressures between 35 and $45 \mathrm{GPa}$ (Stöffler 1971, 1972, 1974; Stöffler et al. 1991; Engelhardt et al. 1967). With increasing peak pressure in plagioclase, there is a progression of deformation from optical extinction to undulatory extinction and partial isotropization, to planar deformation fractures, and finally to planar deformation features (Stöffler 1971, 1972; Stöffler et al. 1991). At higher peak pressures, melting and/or high-pressure phase 
transformations can occur (Stöffler 1971, 1972; Stöffler et al. 1991).

Traditionally, studies of structure and deformation in naturally shocked plagioclase (both terrestrial and extraterrestrial) have consisted of optical microscopy supplemented with X-ray, infrared, and/or Raman spectroscopy (Diemann and Arndt 1984; Fritz et al. 2005; Hörz and Quaide 1973; Jaret et al. 2014, 2015; Pickersgill et al. 2013; Velde et al. 1989; Sims et al. 2019) to better understand the shock and thermal history of meteorites and impactites (Bischoff and Stöffler 1992; Dence et al. 1977; Sharp and DeCarli 2006; Short 1970; and Stöffler et al. 1991). A number of researchers have conducted experimental studies intended to evaluate and understand deformation in plagioclase under known or calibrated conditions using either dynamic shock experiments, or static diamond anvil cell (DAC) as discussed in detail in Sims et al. (2019).

A critical note about experiments performed in the laboratory should be highlighted here: experimental shock pressures are of much shorter duration compared to those that occur in nature, whereas those from static compression are much longer (Langenhorst and Hornemann 2005). This is because the pressure at which plagioclase amorphizes is dependent on strain rate (Sims et al. 2019) and potentially on $\mathrm{P}-\mathrm{T}$ path. The duration of peak pressure is not typically standardized and remains largely unstudied (Carl et al. 2017), as is quench rate, which can differ from compression rate (Langenhorst and Hornemann 2005; Sharp and DeCarli 2006). To investigate the dissimilarities between impact metamorphism and experimental conditions, we examine processes during both compression and decompression in this study, which have not previously been addressed. We study the effect of strain rate, quench rate, and pressure duration on potential phase memory effects, as discussed in previous studies (Daniel et al. 1997; Farber and Williams 1996; Jamet 1988; Sims et al. 2019; Strukov 1989).

\section{Raman spectroscopy of plagioclase under pressure}

This study focuses on using Raman spectroscopy at high pressure to study systematic changes in peak intensity to reveal the response of plagioclase to increasing pressures. Plagioclase has Raman-active vibrational modes belonging to the tetrahedra, tetrahedral framework, and lattice (Sharma et al. 1983). The Raman peaks of plagioclase were classified by Freeman et al. (2008) based on calculations from McKeown (2005) into five groups. The classifications are based on vibrational modes of the $\mathrm{TO}_{4}$ tetrahedra ( $\mathrm{T}$ is $\mathrm{Al}$ or $\mathrm{Si})$. Group I features are due to stretching modes (450-520 $\Delta \mathrm{cm}^{-1}$ ). Group II/III features are due to rotation/translational modes and include peaks from 240 to $300 \Delta \mathrm{cm}^{-1}$ and from 150 to $210 \Delta \mathrm{cm}^{-1}$, respectively. Group IV features are due to deformation modes and are found from 550 to $830 \Delta \mathrm{cm}^{-1}$.
Group V includes anti-symmetric vibrational stretching modes that occur from $~ 875$ to $1200 \Delta \mathrm{cm}^{-1}$. More detailed modeling of albite by Aliatis et al. (2017) recognized and assigned 39 modes and provided more specific information about the atomic vibrations and motions, with particular focus on the $\mathrm{Na}^{+}$configuration.

Multiple studies have used Raman spectroscopy as a measure of crystallographic deformation associated with progressive amorphization in response to compression (Fritz et al. 2005; Heymann and Hörz 1990). Velde et al. (1989) analyzed Raman spectra of three different feldspar compositions experimentally shocked from 21 to $54 \mathrm{GPa}$ using both $488 \mathrm{~nm}$ and $514.5 \mathrm{~nm}$ lasers. They found that albite exhibited the greatest resiliency to shock pressure and suggested that the lattice of shocked albite responds differently between shock and static compression. Because memory effects do not occur in albite (Tomioka et al. 2010), the Na endmember of plagioclase, observation of amorphization on multiple members of the plagioclase system is necessary. Memory effects may not occur in albite possibly due to the differences in the degree of structural reorientation and amount of broken bonds (Mookherjee et al. 2016) between the plagioclase endmembers' proposed amorphous structures. Raman spectra of minerals subjected to high static pressures in DACs have been acquired to study terrestrial mantle properties (Daniel et al. 1995, 1997; Farber and Williams 1996; Kubicki et al. 1992). The largest Raman peak, $503 \Delta \mathrm{cm}^{-1}$ in anorthite, corresponds to symmetric stretching motions of oxygen atom along the line bisecting the T-O-T line (Daniel et al. 1997; Freeman et al. 2008). Daniel et al. (1997) showed that above $10 \mathrm{GPa}$, the 503 $\Delta \mathrm{cm}^{-1}$ peak merged with the $513 \Delta \mathrm{cm}^{-1}$ peak. Around the same pressure, the peak shift with pressure was less, corresponding to $\sim 1.51 \Delta \mathrm{cm}^{-1} \mathrm{GPa}^{-1}$. Between 14.1 and 15.4 $\mathrm{GPa}$, Raman active $\mathrm{Si}-\mathrm{O}-\mathrm{Al}$ bending and stretching modes broadened, indicating deformation of $\mathrm{Si}$ and $\mathrm{Al}$ tetrahedral bonds (Daniel et al. 1997). There was also a decrease in the peak intensity of all bands. All anorthite peaks disappeared between 15.4 and 16.0 GPa. Amorphous anorthite Raman spectra contained broad bands in the $\mathrm{Si}-\mathrm{O}-\mathrm{Al}$ stretching region from 900 to $1300 \Delta \mathrm{cm}^{-1}$ (Daniel et al. 1997).

Recovered experimentally shocked samples also show changes in their Raman spectra in response to shock (Heymann and Hörz 1990; Jaret et al. 2018). Heymann and Hörz (1990) acquired Raman spectra with a $488 \mathrm{~nm}$ laser of oligoclase $\left(\mathrm{An}_{19}\right)$ and andesine $\left(\mathrm{An}_{49}\right)$ experimentally shocked at pressures from 24 to $40 \mathrm{GPa}$. They noted the broadening and/or loss of many spectral peaks with increasing pressure, culminating in the disappearance of the $\mathrm{Si}-\mathrm{O}-\mathrm{Al}$ stretch bands at $>30 \mathrm{GPa}$ (where the transition to diaplectic glass nears completion). Daniel et al. (1995) noted the appearance of a broad, medium-intensity band around 1000 $\Delta \mathrm{cm}^{-1}$ in the Raman spectrum of shocked anorthite. This 
was similar to the result of Freeman et al. (2008), who presented Raman spectra of a variety of plagioclase feldspars, including a shocked anorthite from lunar meteorite NWA 773 that showed broadening of bandwidths with pressure, consistent with partial conversion to maskelynite. Fritz et al. (2005) used Raman measurements to quantify shock effects in meteorites through detailed analyses of maskelynite. They demonstrated that the progression in shock pressures, as indicated by refractive index changes, can be matched to characteristic degradation of the Raman spectra. However, they did not measure materials subjected to shock pressures lower than those required for maskelynite formation, and they did not correlate their measurements to petrographic textures, but only to refractive index.

\section{Experiments and methods}

We conducted a series of experiments focused first on andesine, supplemented with experiments on albite, to test the stability field of amorphous plagioclase and its ability to become a memory glass. Specifically, we consider pressure, time, and strain rate. We apply non-traditional experimental techniques to amorphization in plagioclase. We used two samples. The albitite sample (97-99\% $\mathrm{Ab}_{98}$ with minor amounts of sericite, quartz, potassium feldspar, and amphibole) originated from Szklary (Lower Silesia), Poland (Muszynski and Natkaniec-Nowak 1992). The andesine sample (95\% $\mathrm{An}_{36-46}$ ) originated from St. Urbain province, Quebec, Canada, (STU06-1688). It contained minor amounts of quartz and potassium feldspar (Owens and Dymek 2001). See Johnson et al. (2002; 2003) and Johnson (2012) for sample details.

\section{Micro-Raman analyses}

All micro-Raman measurements were completed at the Center for Planetary Exploration (CPEx) at Stony Brook University. Spectra were acquired using a WiTec alpha300R confocal imaging system using a $532 \mathrm{~nm}$ Nd YAG laser with $2.24 \mathrm{~mW}$ nominal power and a 50X $(\mathrm{NA}=0.5)$ long working distance objective with a spot size of $763 \mathrm{~nm}$. Multiple spots on the sample were examined, and representative spectra are presented. Each Raman analysis consisted of 240 summed $1 \mathrm{~s}$ accumulations.

\section{DAC experimental setup}

We collected in situ Raman spectra (100-1200 $\left.\Delta \mathrm{cm}^{-1}\right)$ on a plagioclase single crystal in a DAC as the grain was incrementally and statically compressed and then decompressed through a series of pressures. The diamonds had culet sizes of $450 \mu \mathrm{m}$. Single grains of plagioclase (approx.
$40 \times 40 \mu \mathrm{m})$ were taken from each starting sample. Pseudohydrostaticity on the sample was maintained by placing the sample between layers of pre-compressed $\mathrm{NaCl}$ (Klotz et al. 2009). The surrounding volume was then filled with additional $\mathrm{NaCl}$, which does not occlude or interfere with the Raman signal from the sample. We chose $\mathrm{NaCl}$ as a medium due to its low yield stress (Duffy 2007). $\mathrm{NaCl}$ is incapable of supporting high differential stresses ( $<2.5 \mathrm{GPa}$ maximum), and therefore limits shear forces. Several rubies were added to measure pressure using the ruby fluorescence technique (Dewaele et al. 2008; Mao et al. 1986) which generally has errors of $\sim 0.2-0.3 \mathrm{GPa}$. The average of multiple ruby measurements was used when available.

\section{Experimental series}

Two samples were used in a total of eight compression experiments. The initial spectroscopic patterns are shown in Figs. 3 and 4 from 1.0 GPa to demonstrate the background behavior for spectra taken through the diamonds at low pressure. Whenever possible, we verified that the samples remained amorphous by using the Raman instrument to examine the grains after decompression with the upper diamond removed. Experiment 1 consisted of stepwise compression and decompression of andesine. Andesine was compressed to $17.9 \mathrm{GPa}$ in a stepwise fashion, stopping at 0.6 GPa, 1.0 GPa, 5.2 GPa, 6.4 GPa, 7.5 GPa, 8.2 GPa, 9.5 GPa, 10.1 GPa, 12.1 GPa, 14.9 GPa, and 17.9 GPa. Raman spectra were acquired at each pressure. After sitting at 17.9 GPa for $5 \mathrm{~min}$, the sample was then decompressed in a series of steps stopping at $15.6 \mathrm{GPa}, 11.0 \mathrm{GPa}, 9.3 \mathrm{GPa}, 6.7 \mathrm{GPa}$, $2.8 \mathrm{GPa}$, and $0.6 \mathrm{GPa}$, with Raman spectra acquired at each pressure. In Experiment 2, andesine was compressed to 18.1 $\mathrm{GPa}$, stopping at $1.9 \mathrm{GPa}, 8.1 \mathrm{GPa}, 10.2 \mathrm{GPa}, 13.5 \mathrm{GPa}, 15.8$ $\mathrm{GPa}$, and $18.1 \mathrm{GPa}$. Raman spectra were acquired at each pressure. The sample was then kept in the DAC at $18.1 \mathrm{GPa}$ for 59 days before quenching. Here, we use the term quench to indicate decompression from high pressure to ambient in one step, and does not involve or refer to temperature, melting, or any liquid phases.

Experiment 3 involved quenching andesine directly from a peak pressure of $18 \mathrm{GPa}$. Andesine was compressed almost directly to $18 \mathrm{GPa}$ and then quenched immediately. No sample measurements were acquired during compression. Pressure increase was paused only long enough to determine the pressure on the sample. Sample spectra were acquired prior to compression and post-quench. Experiment 4 was similar to Experiment 3 and involved quenching andesine directly from $20.3 \mathrm{GPa}$. The quench and spectral acquisition occurred similarly.

Experiment 5 involved dropping a DAC approximately $1 \mathrm{~m}$, which we hereafter refer to as DAC-drop. To test the effects of rapid pressure increases once at high pressure, 
andesine was compressed to $17.7 \mathrm{GPa}$. Then, the entire cell was dropped onto a plastic table from $1 \mathrm{~m}$ height. The cell was dropped carefully to ensure that it landed parallel to the compression axis of the diamonds. Sample spectra were acquired pre-drop and post-quench. During Experiment 6, andesine was compressed to $18 \mathrm{GPa}$ and then the DAC was struck with a wooden mallet. A metal plate was placed on top of the cell prior to striking to ensure that pressure was applied uniformly and that the strike was parallel to the compression axis of the diamonds (see supplementary video file). Sample spectra were acquired after pre-compression, at $18 \mathrm{GPa}$, and post-quench.

The final experiment was conducted on albite and utilized a methodology similar to Experiments 1 and 2, for which Raman spectra were acquired at every pressure step. Experiment 7 consisted of compressing albite to $39 \mathrm{GPa}$, stopping at $12 \mathrm{GPa}, 14.6 \mathrm{GPa}, 27.4 \mathrm{GPa}$ and $39.9 \mathrm{GPa}$. It was then quenched immediately.

\section{Spectral processing}

Raman spectra were not corrected for background fluorescence. Several locations on each sample were examined to verify the uniformity of deformation and the spectra shown are representative. Pressure steps were not uniform due to the difficulty of estimating pressure during manual pressure change. The peak at $305 \Delta \mathrm{cm}^{-1}$ in each spectrum is an artifact produced by a hot pixel on the detector.

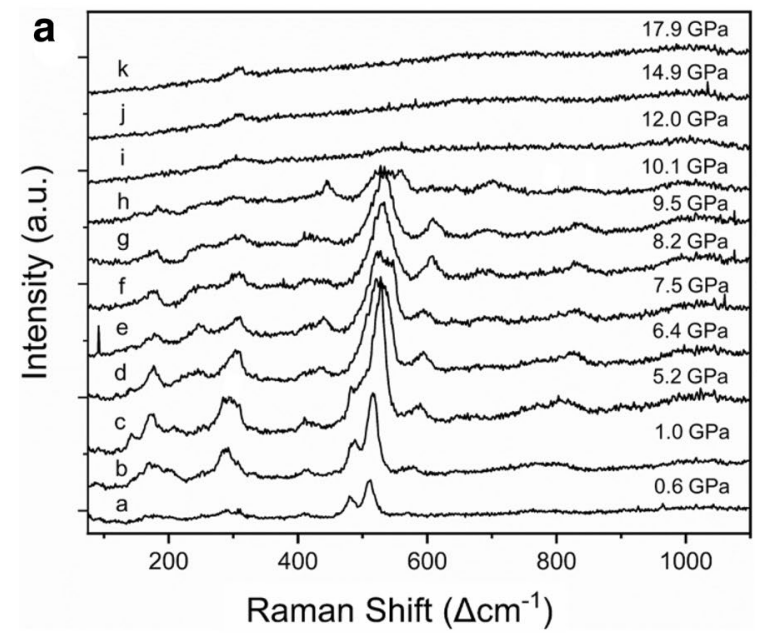

\section{Results}

Prior to compression during Experiment 1, andesine exhibited micro-Raman spectra with characteristic peaks at 287 , $\sim 480$, and $510 \Delta \mathrm{cm}^{-1}$ with additional peaks near 410 and $571 \Delta \mathrm{cm}^{-1}$ (Fig. 1a). With increasing pressure, two distinct changes occurred to the spectra: (i) all peaks shifted to higher wavenumbers and (ii) all peaks decreased in intensity, most notably the 480 and $510 \Delta \mathrm{cm}^{-1}$ peaks, which were completely lost by $14.9 \mathrm{GPa}$. The peaks at 480 and 510 $\Delta \mathrm{cm}^{-1}$ merged into a single peak centered at $527 \Delta \mathrm{cm}^{-1}$ at pressures above 5.2 GPa. McKeown (2005) indicates that these features correspond to Group I stretching modes and ring breathing modes. Group III modes broadened above 7.5 $\mathrm{GPa}$. Up to $10 \mathrm{GPa}$, there was a decrease in peak intensity, an increase in the peak ratio of the $485-514 \Delta \mathrm{cm}^{-1}$ peaks, and a migration of all peaks to higher wavenumbers. The Group III modes disappeared at $12.0 \mathrm{GPa}$. As indicated by the total absence of peaks, amorphization occurred between 12 and $18 \mathrm{GPa}$. On decompression (Fig. 1b), the sample reverted to a more crystalline form. The peak intensities of the fully decompressed spectrum were lower than the precompression sample. However, the $485 / 514 \Delta \mathrm{cm}^{-1}$ peak ratios were identical to within the error of the measurement. The peaks in the recovered sample were not broadened compared to the original sample.

For Experiment 2, the sample showed a systematic progression of decreasing peak intensities (Fig. 2a) during progressive compression. All peak positions shifted to higher wavenumbers with increasing pressure. At $18.1 \mathrm{GPa}$, only a broad weak peak at $\sim 580 \Delta \mathrm{cm}^{-1}$ was evident, with no peak intensity from the other peaks remaining. The sample remained at peak pressure for 2 months, during which the

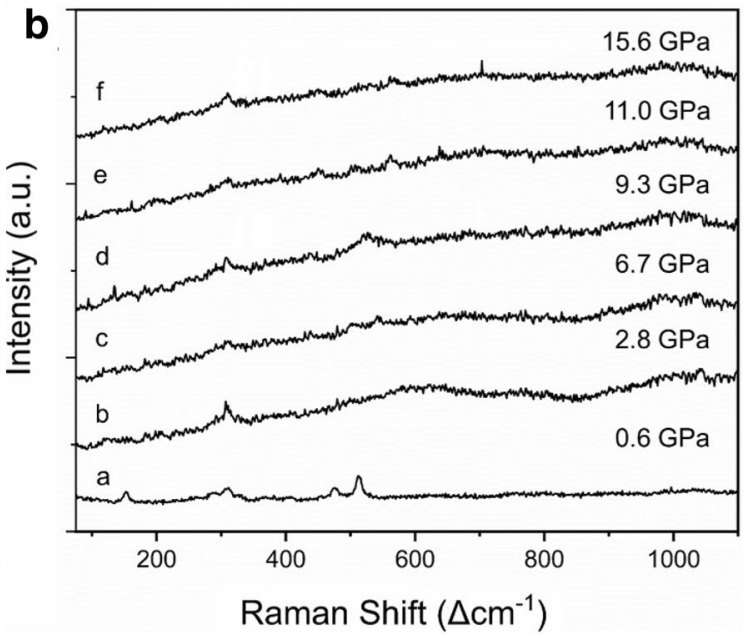

Fig. 1 a Stacked profile of Raman spectra for andesine sample during compression to peak pressure of 17.9 GPa. b Stacked profile of Raman spectra for andesine sample during decompression from 15.6 GPa 


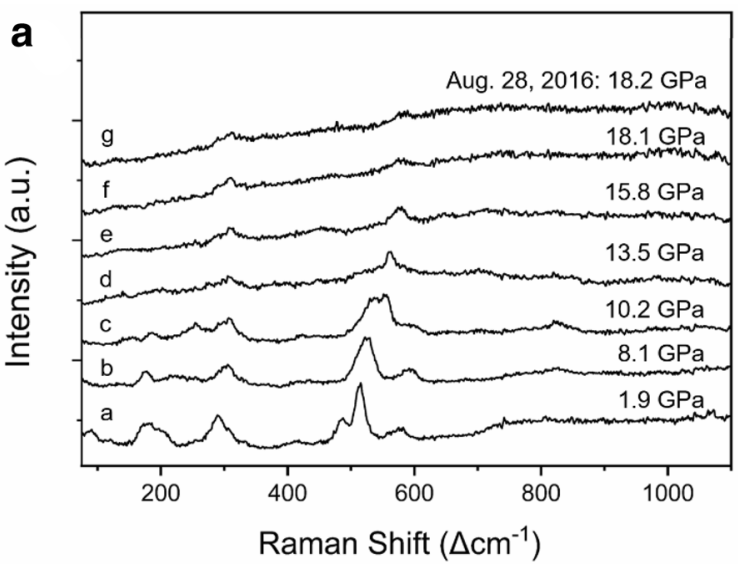

Fig. 2 Stacked profile of Raman spectra for andesine sample left at pressure for 59 days. a Measured pressures appear above each spectrum. The last pressure increase to 18.2 GPa occurred on August 28,

pressure increased slightly to $18.2 \mathrm{GPa}$ (within uncertainty of the measurement). After 59 days, on August 28, 2016, the Raman spectrum appeared to be nearly identical to the Raman spectrum acquired immediately after reaching high pressure (Fig. 2a). After quenching, the peaks did not reappear. The sample was monitored for 12 days after decompression, during which no change was observed.

In the third experiment, andesine was compressed to 18.0 $\mathrm{GPa}$. The compression was followed by immediate quenching. After quenching, the sample exhibited weak peaks at 507 and $478 \Delta \mathrm{cm}^{-1}$ (Fig. 3). In Experiment 4, andesine was compressed to a peak pressure of $\sim 20.3$ in the same manner as Experiment 3. The sample was immediately quenched after pressure measurement. After quenching, the sample did not show any crystalline peaks (Fig. 4b). However, a weak broad peak near $580 \Delta \mathrm{cm}^{-1}$ was observed. The spectra of the quenched samples from Experiments 3 and 4 are compared in Fig. 5.

In Experiment 5, a DAC loaded with andesine was dropped from a height of $1 \mathrm{~m}$. The cell was pre-pressurized as quickly as possible to a pressure of $17.7 \mathrm{GPa}$. The spectrum acquired at $17.7 \mathrm{GPa}$ is shown in Fig. 6b. Only a broad peak near $550 \Delta \mathrm{cm}^{-1}$ was present. After performing the DAC-drop from a height of $1 \mathrm{~m}$, the spectra measured while still under compression remained mostly amorphous, indicating no change to the sample spectrum. After quenching (Fig. 6c), the sample appeared to have somewhat recrystallized, showing a weak peak at $512 \Delta \mathrm{cm}^{-1}$.

For Experiment 6, the andesine sample was compressed as quickly as possible to a peak pressure of $18.0 \mathrm{GPa}$. A spectrum was acquired at $18.0 \mathrm{GPa}$, and the sample was found to be amorphous (Fig. 7b). After hitting the cell with the mallet (see supplementary video), the cell reached an estimated peak pressure of $36 \mathrm{GPa}$ as verified using ruby florescence. The sample was checked to ensure it was

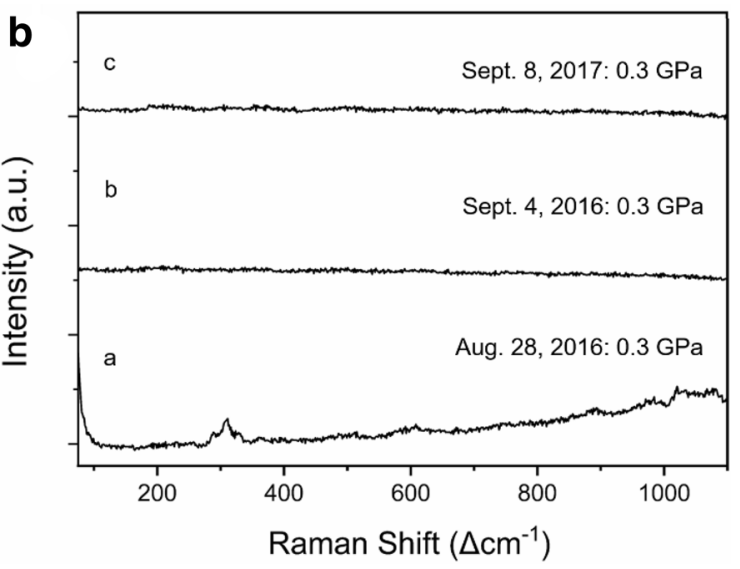

2016. b The pressure and date of each measurement appear above the spectrum. The $310 \Delta \mathrm{cm}^{-1}$ band is an artifact

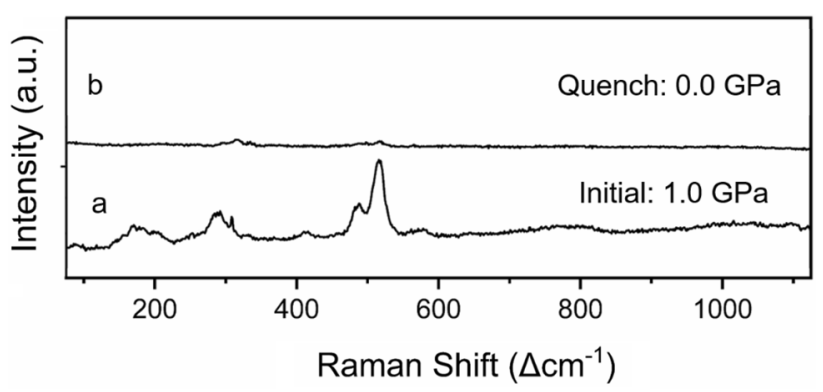

Fig. 3 Spectra of andesine quenched from $18.0 \mathrm{GPa}$. a A typical lowpressure spectrum. b Spectrum of the post-quench sample

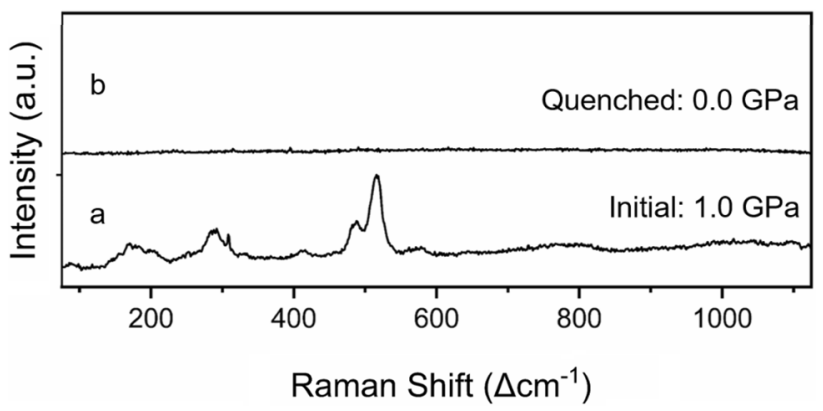

Fig. 4 Spectra of andesine quenched from $20.31 \mathrm{GPa}$. a A typical low-pressure spectrum $\mathbf{b}$ A spectrum from the post-quench sample

amorphous, but in the interest of keeping the residence time as short as possible, no full spectrum from the sample was taken at peak pressure. The post-quench spectra indicated the presence of an amorphous material, with broad peaks near 580, 760, and $1020 \Delta \mathrm{cm}^{-1}$ (Fig. 7c), although crystalline peaks did not reappear (Fig. 7c). 


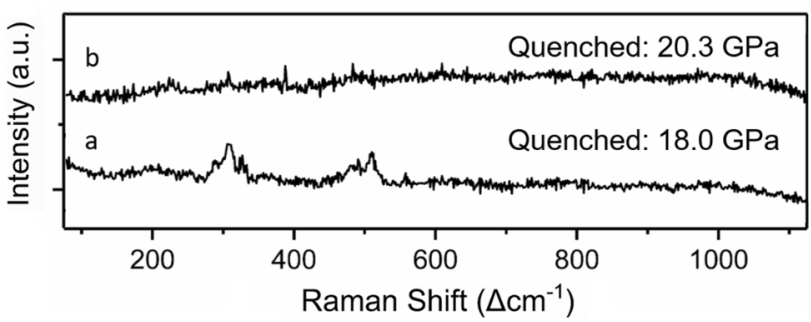

Fig. 5 a Spectra of andesine sample quenched from 18.0 GPa (Fig. 3b). b Quenched from 20.3 GPa (Fig. 4b)

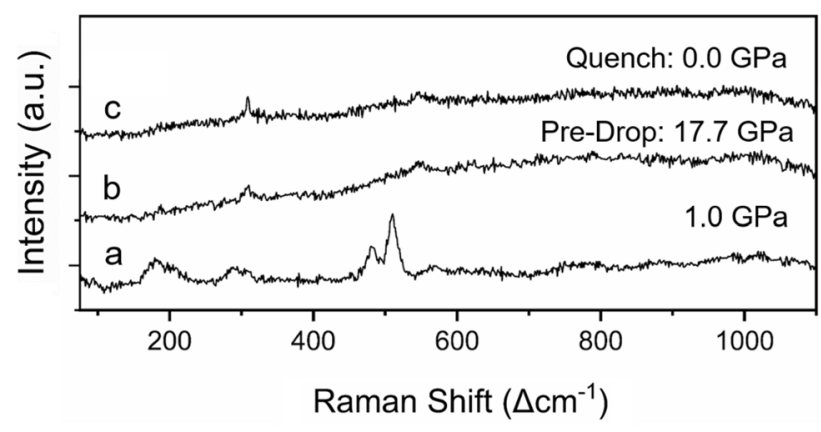

Fig. 6 Raman spectra of andesine from the DAC drop experiment. a A typical low-pressure spectrum before the DAC was compressed and dropped. b Spectrum acquired at a pressure of $17.7 \mathrm{GPa}$ prior to the drop. c Spectrum acquired after sample decompression

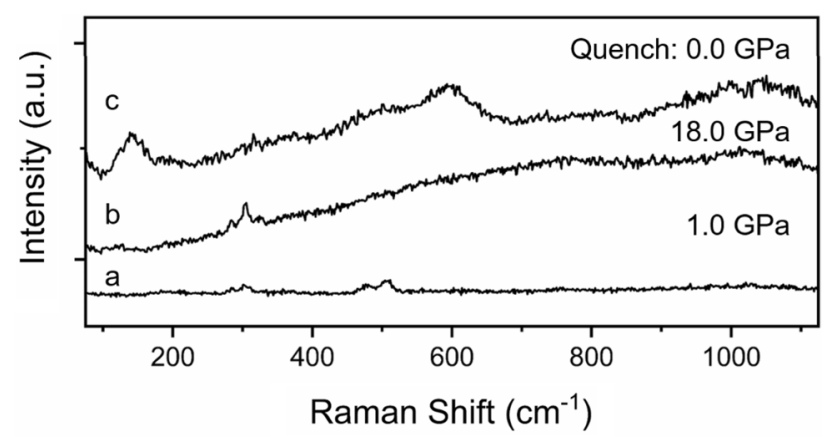

Fig. 7 Raman spectra of sample from SMACA-DAC experiment. a The andesine sample prior to the experiment. b A spectrum from 18.0 $\mathrm{GPa}$. No sample measurements were taken at $36 \mathrm{GPa}$, while the sample was amorphous. c A spectrum from sample post-quench

Experiment 7 utilized an albite sample to examine the effect of Na content. Initially, albite micro-Raman spectra contained characteristic peaks at $\sim 291, \sim 479$, and 507 $\Delta \mathrm{cm}^{-1}$ at $0.0 \mathrm{GPa}$ (Fig. 8). As pressures were increased to $12.0 \mathrm{GPa}$, the 479 and $507 \Delta \mathrm{cm}^{-1}$ peaks merged. The sample became fully amorphous between $27.4 \mathrm{GPa}$ and $39.9 \mathrm{GPa}$. The spectrum from the decompressed sample contained no resolvable peaks.

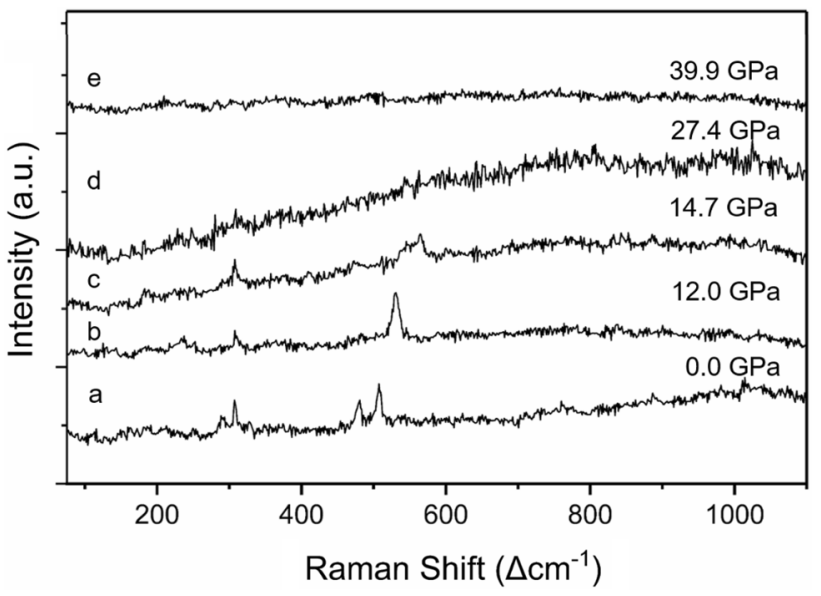

Fig. 8 Stacked profile of Raman spectra for albite sample. Measured pressures appears above each spectrum

\section{Discussion and conclusions}

Daniel et al. (1997) found that anorthite samples can become amorphous, appear amorphous, and then regain crystallinity on decompression. They observe that this behavior is dependent on the peak pressure attained. In this work, we examine this impermanent amorphization. We also study the conditions for the pressure threshold where plagioclase samples remain amorphous upon decompression.

\section{Memory effects}

Prior to compression, feldspar structures contain rings of four and six tetrahedra. The low wavenumber $\left(\sim 200 \Delta \mathrm{cm}^{-1}\right)$ modes disappeared first upon initial compression. McKeown (2005) identified these features as resulting from four-membered ring and tetrahedral cage shear-rotation displacements. The disruption of the low wavenumber modes indicates the structure has been altered in a way that suppresses those motions, while leaving other features unaffected. The loss of these modes may indicate loss of long range order. Other peaks became more distinct at higher pressure, such as the 571-830 $\Delta \mathrm{cm}^{-1}$. Aliatis et al. (2017) attributes these features to deformation of the tetrahedra. The change may be due to either differences in background florescence in that part of the spectrum or simply due to additional deformation. The peaks that disappeared last, between 450 and 520 $\Delta \mathrm{cm}^{-1}$, are characteristic of the feldspar structure (Sharma et al. 1983). McKeown (2005) attributes these peaks to ring breathing modes of the four-membered tetrahedra. The retention of these peaks possibly indicates that a subset of comparatively undeformed rings might persist to higher pressures than other structural features that are characteristic of the crystalline structure. Aliatis et al. (2017) suggests that deformation in Si tetrahedra is greater than that in the 
Al tetrahedra. In andesine, peaks in the decompressed sample were of lower intensity but were not broadened, which may reflect a variety of deformation mechanisms involving the closing up and partial reopening of the crankshaft unit without involving disruption of this unit, similar to what has been suggested for plagioclase deformation (Aliatis et al. 2017; Angel 1988). The peak shift to higher wavenumbers occurred in all samples, indicating decreases in bonding lengths (Hemley et al. 1986). At high pressure, the data suggest that the ring structures were altered such that relevant breathing modes no longer appeared. A nuclear magnetic resonance spectroscopic study by Jaret et al. (2015) suggested that the $\mathrm{T}-\mathrm{O}-\mathrm{T}$ bonding still exists at higher pressures, which our study corroborates.

Andesine appeared to show evidence of pressure-induced memory effects, similar to anorthite as measured by Daniel et al. (1997) and Williams and Jeanloz (1989). Andesine compressed to $\sim 18 \mathrm{GPa}$ reverted back to a crystalline phase upon decompression, albeit with less pronounced spectral peaks than the initial uncompressed sample. This occurred both during stepwise decompression (Fig. 1b) and during immediate quenching (Fig. 3), suggesting that time and kinetics of decompression are not critical to this reversion. However, the peaks from the immediate quench (Fig. 3) experiment were stronger than peaks from the stepwise decompression (Fig. 1b). The reduced intensities may indicate either fewer unaltered structures remain post-experimentation or changes in ring statistics.

Interestingly, the andesine compressed to $20.3 \mathrm{GPa}$ did not revert upon decompression (Fig. 4). This suggests that the atomic displacements induced by compressing to $18 \mathrm{GPa}$ were smaller than those induced by compressing to 20.3 $\mathrm{GPa}$, such that $18 \mathrm{GPa}$ is not sufficient static pressure to cause a complete transformation. The andesine stepwise pressurization experiment (Experiment 1) and the two quench experiments (Experiments 3 and 4) suggest that there may be an energy well around $18 \mathrm{GPa}$ such that an additional energy input is needed to push the system toward a complete transformation. Further, remaining at the critical $18 \mathrm{GPa}$ pressure for 2 months (Fig. 2) was sufficient time for the atoms to arrange themselves in a manner that resists reversion upon decompression. That experiment indicated that time can possibly play as important a role as pressure and strain rate at longer timescales.

To further evaluate this apparent energy well at $\sim 18$ $\mathrm{GPa}$, we tested the effect of sudden addition of energy to the system by dropping the loaded DAC parallel to the diamond's compression axis. Dropping the cell from $1 \mathrm{~m}$ did not provide enough additional energy to push the system to complete amorphization, as shown in Fig. 6, where the post-drop spectra display crystalline peaks at $510 \Delta \mathrm{cm}^{-1}$. We then tested a greater energy spike-directly striking the DAC with a wooden mallet. This was a large enough spike to induce a complete transformation, as shown in Fig. 7. After hitting the cell and subsequently quenching, only a broad peak remained, and the andesine did not revert. Based on the position of ruby fluorescence peaks, we estimate that hitting the cell nearly doubled the pressure from 18 to $36 \mathrm{GPa}$. The diamond anvils were not damaged during the experiment.

This set of non-traditional DAC experiments show that around $18 \mathrm{GPa}\left(\right.$ at $25^{\circ} \mathrm{C}$ ) the system is metastable such that it requires an additional 'kick' to push it over the threshold for complete transformation. This 'kick' is either a change in max P (Experiment 4 and the hammer Experiment 6), more time (Experiment 2), or passage of an acoustic wave through the sample. More so, we show that in the case of passing an acoustic wave through the sample, it requires a significant (although admittedly not quantified) wave. The energy imparted from dropping the DAC from $1 \mathrm{~m}$ was not enough to push the system toward complete amorphization, but hitting it with a hammer was. This shows that the system is metastable with respect to multiple variables beyond the standard $\mathrm{P}$ and $\mathrm{T}$ most commonly discussed.

\section{Amorphization pressures in andesine}

In plagioclase samples, the pressures at which amorphization begins and completes is dependent on a number of variables, including hydrostaticity (deviatoric stress), temperature and compression rate (Daniel et al. 1997; Sims et al. 2019; Tomioka et al. 2010). Deviatoric stress has an effect on amorphization pressures in our samples. In anorthite, Daniel et al. (1997) observed that amorphization initiation and completion pressures were reduced under less hydrostatic conditions. With $\mathrm{NaCl}$ as a medium, deviatoric stress in the diamond anvil cell reaches $2 \mathrm{GPa}$ at enclosure pressures of $5 \mathrm{GPa}$ (Reynard et al. 2019). The deviatoric stress eventually reaches $2.5 \mathrm{GPa}$ at $7 \mathrm{GPa}$ pressure, and it remains at that value up to $20 \mathrm{GPa}$ (Reynard et al. 2019). In andesine, we observe that amorphization begins below $5.3 \mathrm{GPa}$ and is complete by $12 \mathrm{GPa}$. Therefore, both amorphization initiation and completion in andesine are affected by deviatoric stresses of at least $2 \mathrm{GPa}$. Amorphization pressures in andesine might be higher in other mediums. In albite, the effect of deviatoric stress is less obvious. With no pressure medium, Tomioka et al. (2010) found amorphization in albite was complete by $37 \mathrm{GPa}$. We found albite to amorphize between 27 and $39 \mathrm{GPa}$.

Based on the experiments in this study, we infer that amorphization of andesine is displayed in two ways. In the first mode, the sample begins to become amorphous when measured under compression. We interpret this to be the same "amorphization initiation" point that Daniel et al. (1997) described for anorthite under static conditions. The second mode is at higher pressure at which amorphization is complete, such that the sample will remain amorphous 
after decompression. For andesine that did not remain at high pressure for long periods, we observed an initiation of amorphization around $18 \mathrm{GPa}$, whereas amorphization was complete around $21 \mathrm{GPa}$. These values are higher than those reported for anorthite by Daniel et al. (1997), but this is expected because of known compositional effects on amorphization point in feldspars (e.g., Kubo et al. 2010). For example, in prior DAC and shock experiments (Daniel et al. 1997; Redfern 1996), more calcic feldspars transformed at lower pressures. While this has been described in terms of Ca content previously, it likely is not related to the calcium itself, but rather by the subsequent $\mathrm{Al}$ bonding changes that result from the coupled substitution in plagioclase. Amorphization typically involves changes in the $\mathrm{Si}-\mathrm{O}$ tetrahedral Si-polymerization, and therefore changing the Al-Si ratio will change the ordering in the feldspars. The more calcic (or more Al rich) plagioclase may not have the same bonding capability as a more sodic (with more $\mathrm{Si}-\mathrm{O}$ tetrahedra) plagioclase.

Generally, the different plagioclase compositions had similar behavior with increasing pressure. The peaks shifted to higher wavenumbers with increasing pressure, indicating reduction in size of the rings of tetrahedra. The peaks broadened and intensity decreased, indicating a variety of local environments and fewer Raman active vibrational modes. The last sharp features to be lost were the $560 \Delta \mathrm{cm}^{-1}$ peak and the largest peak, $520 \Delta \mathrm{cm}^{-1}$ here. Based on work by McKeown (2005) and Freeman et al. (2008), these features can be attributed to Group V deformation modes and Group I s bending deformation of the $\mathrm{T}-\mathrm{O}-\mathrm{T}$ bonds. The changes indicate structure has been altered in a way that suppresses that motion.

We mainly focused on andesine because previous work focused on nearly pure-Ca endmember compositions where memory effects were noted (Daniel et al. 1997), but other transformations in plagioclase (particularly transformation to the high-pressure polymorph tissintite (Ma et al. 2014; Rucks et al. 2018) seem to require intermediate compositions. Therefore, our experiments are supplemented with work on albite, in which we observed amorphization at significantly lower pressures (27.4-39.9 GPa) than is found in shock experiments (50-56 GPa; Jaret et al. 2016; Johnson and Hörz 2003).

\section{Implication for pressure barometry of natural samples}

The memory effect seen in these experiments presents some complications for barometric studies of natural materials-particularly shocked rocks. The influence of temperature on the memory effect is not clear. For studies of naturally shocked materials, measurements are conducted on samples that have been fully decompressed, and Raman spectra, particularly peak intensity ratios, are used to assign a pressure estimate (e.g., Fritz et al. 2005). We demonstrate that amorphization is affected by the length of time at peak pressure as well as the peak pressure reached and the time required to reach the said peak pressure. When a sufficiently high pressure is reached, the memory effect is lost. However, we show that crystalline peaks partially return for samples below the amorphization completion point when subjected to static pressures. While further experiments would be useful, the DAC strike and DAC drop experiments suggest the effect may occur in shock experiments with peak pressures below $36 \mathrm{GPa}$, but experiencing a high strain rate during compression. Bearing in mind the differences between static compression and natural impacts, it may therefore be very difficult to distinguish between samples that were compressed to low peak pressures from those that have actually seen higher pressures but have reverted. In this case, the actual peak pressures seen would not be known as the post-decompression measurements would be recording the reverted crystalline structure and therefore one could drastically underestimate the actual peak pressures seen in these materials during shock compression (Fig. 3). This may also partially explain some of the discrepancy in "amorphization pressure" observed between static in situ and shock experiments. Shock experiments typically indicate higher amorphization $\mathrm{P}$ than static compression, but this may be reflecting the ultimate max $\mathrm{P}$ for amorphization completion rather than the initial amorphization onset observed by in situ measurements.

Acknowledgements This work was supported by Planetary Geology and Geophysics grant NNX14AN33G and the RIS4E node of the Solar System Exploration Research Virtual Institute (SSERVI). This work was also supported by Ames Research Center (Grant No. NNA14AB05A). We would also like to thank Dr. Lars Ehm for the use of his equipment and Dr. Anna Plonka for assistance with the experiments. The spectral data presented in the figures will be made available at the Stony Brook University Academic Commons archive at: https:// commons.library.stonybrook.edu/.

Open Access This article is licensed under a Creative Commons Attribution 4.0 International License, which permits use, sharing, adaptation, distribution and reproduction in any medium or format, as long as you give appropriate credit to the original author(s) and the source, provide a link to the Creative Commons licence, and indicate if changes were made. The images or other third party material in this article are included in the article's Creative Commons licence, unless indicated otherwise in a credit line to the material. If material is not included in the article's Creative Commons licence and your intended use is not permitted by statutory regulation or exceeds the permitted use, you will need to obtain permission directly from the copyright holder. To view a copy of this licence, visit http://creativecommons.org/licenses/by/4.0/. 


\section{References}

Aliatis I, Lambruschi E, Mantovani L, Bersani D, Gatta GD, Tribaudino M, Lottici PP (2017) High-pressure Raman spectroscopy on low albite. Phys Chem Min 44:213-220

Angel RJ (1988) High-pressure structure of anorthite. Am Mineral 73:1114-1119

Arndt J, Hummel W, Gonzalezcabeza I (1982) Diaplectic labradorite glass from the Manicouagan impact crater. 1. physical-properties, crystallization, structural and genetic-implications. Phys Chem Miner 8(5):230-239. https://doi.org/10.1007/bf00309482

Bischoff A, Stoffler D (1992) Shock metamorphism as a fundamental process in the evolution of planetary bodies-information from meteorites. Eur J Mineral 4(4):707-755

Bunch TE, Cohen AJ, Dence MR (1967) Natural terrestrial maskelynite. Am Mineral 52(1-2):244-253

Carl ER, Mansfeld U, Liermann HP, Danilewsky A, Langenhorst F, Ehm L, Trullenque G, Kenkmann T (2017) High-pressure phase transitions of $\alpha$-quartz under nonhydrostatic dynamic conditions: a reconnaissance study at PETRA III. Meteorit Planet Sci 52(7):1465-1474. https://doi.org/10.1111/maps.12840

Chao ECT (1968) Pressure and temperature histories of impact metamorphosed rocks-based on petrographic observations. Mono Book Corp, Baltimore

Daniel I, Gillet P, Ghose S (1995) A new high-pressure phase transition in anorthite $\left(\mathrm{CaAl}_{2} \mathrm{Si}_{2} \mathrm{O}_{8}\right)$ revealed by Raman spectroscopy. Am Mineral 80:645-648

Daniel I, Gillet P, McMillan PF, Wolf G, Verhelst MA (1997) Highpressure behavior of anorthite: compression and amorphization. J Geophys Res Solid Earth 102(B5):10313-10325. https://doi. org/10.1029/97jb00398

DeCarli PS, Jamieson JC (1961) Formation of diamond by explosive shock. Science 133(3467):1821-1822. https://doi.org/10.1126/ science.133.3467.1821

Dence MR, Grieve RAF, Robertson PB (1977) Terrestrial impact structures: principal characteristics and energy considerations. In: Roddy DJ, Pepin RO, Merrill RB (eds) Impact and explosion cratering. Pergamon Press, New York, pp 247-275

Dewaele A, Torrent M, Loubeyre P, Mezouar M (2008) Compression curves of transition metals in the Mbar range: experiments and projector augmented-wave calculations. Phy Rev B 78(10): 104102

Diemann E, Arndt J (1984) Diaplectic labradorite glass from the manicouagan impact crater. 2. x-ray-diffraction studies and structural model. Phys Chem Min 11(4):178-181. https://doi.org/10.1007/ bf00387849

Duffy TS (2007) Strength of materials under static loading in the diamond anvil cell. AIP Conf Proc 955:639-644

Engelhardt VW, Bertsch W, Stöffler D, Groschopf P, Reiff W (1967) Anzeichen für den meteoritischen Ursprung des Beckens von Steinheim. Sci Nat 54(8):198-199. https://doi.org/10.1007/BF005 94515

Farber DL, Williams Q (1996) An in situ Raman spectroscopic study of $\mathrm{Na}_{2} \mathrm{Si}_{2} \mathrm{O}_{5}$ at high pressures and temperatures; structures of compressed liquids and glasses. Am Mineral 81(3-4):273-283. https ://doi.org/10.2138/am-1996-3-402

Freeman JJ, Wang A, Kuebler KE, Jolliff BL, Haskin LA (2008) Characterization of natural feldspars by Raman spectroscopy for future planetary exploration. Can Mineral 46:1795-1818

French BM, Short NM (1968) Shock metamorphism of natural materials. Mono Book Corporation, Baltimore

Fritz J, Greshake A, Stöffler D (2005) Micro-Raman spectroscopy of plagioclase and maskelynite in Martian meteorites: evidence of progressive shock metamorphism. Antarct Meteorol Res 18:96
Gillet P, El Goresy A (2013) Shock events in the solar system: the message from minerals in terrestrial planets and asteroids. Annu Rev Earth Planet Sci 41:257-285. https://doi.org/10.1146/annur ev-earth-042711-105538

Hemley RJ, Mao HK, Bell PM, Mysen BO (1986) Raman spectroscopy of $\mathrm{SiO}_{2}$ glass at high pressure. Phys Rev Lett 57(6):747750. https://doi.org/10.1103/PhysRevLett.57.747

Heymann D, Horz F (1990) Raman-spectroscopy and X-ray diffractometer studies of experimentally produced diaplectic feldspar glass. Phys Chem Miner 17(1):38-44. https://doi.org/10.1007/ bf00209224

Hörz F, Quaide WL (1973) Debye-Scherrer investigations of experimentally shocked silicates. Moon 6(1):45-82. https://doi. org/10.1007/bf02630652

Jamet JP (1988) Defect-density waves and memory effects in modulated systems. Phase Transit 11(1-4):335-371. https://doi. org/10.1080/01411598808245493

Jaret SJ, Kah LC, Harris RS (2014) Progressive deformation of feldspar recording low-barometry impact processes, Tenoumer impact structure Mauritania. Meteorit Planet Sci 49(6):10071022. https://doi.org/10.1111/maps. 12310

Jaret SJ, Woerner WR, Phillips BL, Ehm L, Nekvasil H, Wright SP, Glotch TD (2015) Maskelynite formation via solid-state transformation: evidence of infrared and X-ray anisotropy. J Geophys Res Planets 120(3):570-587

Jaret SJ, Johnson JR, Sims M, Glotch TD (2016) Micro-Raman spectroscopy of experimentally shocked albite. Lunar Planet Sci Conf 47:1530

Jaret SJ, Johnson JR, Sims M, DiFrancesco N, Glotch TD (2018) Microspectroscopic and petrographic comparison of experimentally shocked albite, andesine, and bytownite. J Geophys Res Planets 123(7):1701-1722. https://doi.org/10.1029/2018J E005523

Johnson JR (2012) Thermal infrared spectra of experimentally shocked andesine anorthosite. Icarus 221:359-364

Johnson JR, Hörz F (2003) Visible/near-infrared spectra of experimentally shocked plagioclase feldspars. J Geophys Res-Planet 108:5120

Johnson JR, Hörz F, Lucey PG, Christensen PR (2002) Thermal infrared spectroscopy of experimentallyshocked anorthosite and pyroxenite: Implications for remote sensing of Mars. J Geophys Res-Planet 107(E10):5073. https://doi.org/10.1029/2001JE001517

Johnson JR, Horz F, Staid MI (2003) Thermal infrared spectroscopy and modeling of experimentally shocked plagioclase feldspars. Am Mineral 88:1575-1582

Klotz S, Chervin JC, Munsch P, Marchand GL (2009) Hydrostatic limits of 11 pressure transmitting media. J Phys D42(7):075413

Kubicki JD, Hemley RJ, Hofmeister AM (1992) Raman and infrared study of pressure-induced structural changes in $\mathrm{MgSiO}_{3}$, $\mathrm{CaMgSi}_{2} \mathrm{O}_{6}$, and $\mathrm{CaSiO}_{3}$ glasses. Am Mineral 77(3-4):258-269

Kubo T, Kimura M, Kato T, Nishi M, Tominaga A, Kikegawa T, Funakoshi K-i (2010) Plagioclase breakdown as an indicator for shock conditions of meteorites. Nat Geosci 3(1):41-45. https:// doi.org/10.1038/ngeo704

Langenhorst F, Hornemann U (2005) Shock experiments on minerals: basic physics and techniques. EMU Notes Mineral 7:357-387

Ma C, Tschauner O, Beckett JR, Liu Y, Rossman GR, Zuravlev K, Prakapenka V, Dera P, Taylor LA (2014) Tissintite, (Ca, Na) $\mathrm{AlS}_{\mathrm{i}} 2_{\mathrm{O}} 6$ : a shock-induced clinopyroxene in the tissint meteorite. Meteorit Planet Sci 49:A249-A249

Mao HK, Xu J, Bell PM (1986) Calibration of the ruby pressure gauge to 800 kbar under quasi-hydrostatic conditions. J Geophys Res Solid Earth 91(B5):4673-4676. https://doi.org/10.1029/JB091 iB05p04673 
McKeown DA (2005) Raman spectroscopy and vibrational analyses of albite: from $25{ }^{\circ} \mathrm{C}$ through the melting temperature. Am Mineral 90(10):1506-1517

Milton DJ, de Carli PS (1963) Maskelynite: formation by explosive shock. Science 140(3567):670-671. https://doi.org/10.1126/scien ce. 140.3567 .670

Mookherjee M, Mainprice D, Maheshwari K, Heinonen O, Patel D, Hariharan A (2016) Pressure induced elastic softening in framework aluminosilicate-albite $\left(\mathrm{NaAlSi}_{3} \mathrm{O}_{8}\right)$. Sci Rep. https://doi. org/10.1038/srep34815

Muszynski M, Natkaniec-Nowak L (1992) Albitites and oligoclasite from Szklary [Lower Silesia]. Bull Pol Acad Earth 40:2

Owens BE, Dymek RF (2001) Petrogenesis of the Labrieville alkalic anorthosite massif, Grenville Province. Quebec J Petrol 42(8):1519-1546

Pickersgill AE, Flemming RL, Osinski GR, Singleton AC (2013) Micro-X-ray diffraction patterns of shocked plagioclase from the mistastin lake impact structure, Canada. Meteorit Planet Sci 48:A281-A281

Pickersgill AE, Flemming RL, Osinski GR (2015) Toward quantification of strain-related mosaicity in shocked lunar and terrestrial plagioclase by in situ micro-X-ray diffraction. Meteorit Planet Sci 50(11):1851-1862. https://doi.org/10.1111/maps.12514

Redfern SAT (1996) Length scale dependence of high-pressure amorphization: the static amorphization of anorthite. Mineral Mag 60(400):493-498. https://doi.org/10.1180/minma g. 1996.060.400.10

Reynard B, Caracas R, Cardon H, Montagnac G, Merkel S (2019) High-pressure yield strength of rocksalt structures using quartz Raman piezometry. Comptes Rendus Geosci 351:71-79

Rucks MJ, Whitaker ML, Glotch TD, Parise JB, Jaret SJ, Catalano T, Dyar MD (2018) Making tissintite: mimicking meteorites in the multi-anvil. Am Mineral 103(9):1516-1519. https://doi. org/10.2138/am-2018-6539

Sharma SK, Simons B, Yoder HS (1983) Raman-study of anorthite, calcium tschermak pyroxene, and gehlenite in crystalline and glassy states. Am Mineral 68:1113-1125

Sharp TG, DeCarli P (2006) Shock effects in meteorites. In: Lauretta DS, McSween HY (eds) Meteorites and the early solar system II. University of Arizona Press, Arizona, pp 653-677
Short NM (1970) Progressive shock metamorphism of quartzite ejecta from the sedan nuclear explosion crater. J Geol 78(6):705-732. https://doi.org/10.1086/627572

Sims M et al (2019) Pressure-induced amorphization in plagioclase feldspars: a time-resolved powder diffraction study during rapid compression. Earth Planet Sci Lett 507:166-174

Strukov BA (1989) Global hysteresis in ferroelectrics with incommensurate phases. Phase Transit 15(2-3):143-179. https://doi. org/10.1080/01411598908206844

Stöffler D (1971) Progressive metamorphism and classification of shocked and brecciated crystalline rocks at impact craters. J Geophys Res 76(23):5541-5551. https://doi.org/10.1029/JB076i023p 05541

Stöffler D (1972) Deformation and transformation of rock-forming minerals by natural and experimental shock processes. I-behavior of minerals under shock compression. Fortschr Mineral 49:64

Stöffler D (1974) Deformation and transformation of rock-forming minerals by natural and experimental shock processes. II. Fortschr Mineral 51:256-289

Stöffler D, Keil K, Scott ERD (1991) Shock metamorphism of ordinary chondrites. Geochim Cosmochim Acta 55(12):3845-3867. https ://doi.org/10.1016/0016-7037(91)90078-j

Tomioka N, Kondo H, Kunikata A, Nagai T (2010) Pressure-induced amorphization of albitic plagioclase in an externally heated diamond anvil cell. Geophys Res Lett 37:L21301. https://doi. org/10.1029/2010g1044221

Tschermak MG (1872) Sitzungsberichte der Matematisch-Naturwissenschaftlichen Classe de kaiserlichen Akademie der Wissenschaften LXV.:122-146

Velde B, Syono Y, Kikuchi M, Boyer H (1989) Raman microprobe study of synthetic diaplectic plagioclase feldspars. Phys Chem Miner 16(5):436-441

Williams Q, Jeanloz R (1989) Static amorphization of anorthite at 300 $\mathrm{K}$ and comparison with diaplectic glass. Nature 338:413

Publisher's Note Springer Nature remains neutral with regard to jurisdictional claims in published maps and institutional affiliations. 